\title{
Analytical Authentication and Determination of Adulteration in Branded Honey Samples Collected from Selected Areas in Ethiopia
}

\author{
Bamlaku Abebaw \\ Jinka University Department of Chemistry, PO box 165, Jinka, Ethiopia \\ Simegn Serka \\ College of Natural and Computational Science, Department of Chemistry, Hawassa University \\ PO box 05, Hawassa, Ethiopia \\ Alemayehu P. Washe \\ College of Natural and Computational Science, Department of Chemistry, Hawassa University \\ PO box 05, Hawassa, Ethiopia
}

\begin{abstract}
Honey adulteration is a topical issue because increasingly sophisticated adulteration methods are constantly being developed for gaining more profit. This study was conducted to determine adulteration by sugar syrups in selected honey samples of different botanical [Geteme ("Schefflera abbyssinica") Bisana ("Crotonma crostachyus") and Coffee ("Coffee abyssinica)] and geographical (Bore, Keffa and Yirgachefe) origins. The qualitative screening and quantification of sugars were carried out using high performance liquid chromatography to determine adulteration and other parameters such as; moisture content, total solid, ash content and $\mathrm{pH}$ value to ascertain the authenticity of samples. The moisture content, ash content, $\mathrm{pH}$ values of all the honey samples considered in this study ranged from $17.42 \pm 1.46$ to $25.07 \pm 0.75 \%, 0.35 \pm 0.12$ to $0.77 \pm 0.30 \%$ and $3.60 \pm 0.67$ to $3.92 \pm 0.59 \%$, respectively. The results of qualitative screening indicated presence of fructose and glucose in all samples and vanishingly small amount of sucrose in almost all of the analyzed samples. However, the quantification revealed differing level of concentration of sugars. The sucrose content in the current study ranged between 0.00 and 1.03 $\mathrm{g} / 100 \mathrm{~g}$; which is consistent with Codex Alimentarius Commission standard $(5 \mathrm{~g} / 100 \mathrm{~g})$. The average sum of fructose and glucose of Bore, Keffa and Yirgachefe are 70.64, 67.37 and 60.97 respectively, and that of fructose/glucose ratios are1.22, 1.46 and 1.02 respectively. The sum of fructose and glucose contents of Geteme, Bisana and Coffee floral origin honey samples were 75.62, 61.62 and 61.12 and that of fructose/glucose ratios are $1.28,1.20$ and 1.42 respectively. Significant $(\mathrm{p}=0.05)$ variations in sugar compositions of honey samples of different botanical and geographical origin were observed. The results of this study indicate that honey samples of Geteme origin are more authentic than Bisana and Coffee floral origins. Bore honey samples were in general, found to be more authentic than Keffa and Yirgachefe although all of the analyzed honey samples were not adulterated by sugar syrups. The quality of the studied honey samples compare favorably with samples in many parts of the world and also meet international standards. Although further study should be made at larger scale to draw a general conclusion, the present findings can serve as back ground information for other researchers who are interested to conduct further study at a wider scale on this area.
\end{abstract}

Keywords: Honey, Adulteration, Authenticity, High performance liquid chromatography

DOI: $10.7176 /$ FSQM/93-01

Publication date: January $31^{\text {st }} 2020$

\section{INTRODUCTION}

Honey is a natural sweet product produced by honey bees (Apismellifera L.) from various secretions of plants. The composition and properties of honey depend on the botanical origin of the source of nectars or secretions [1]. According to the origin, honey can be classified in different categories as follows: (i) blossom honey, obtained predominantly from the nectar of flowers (as opposed to honeydew honey); (ii) honeydew honey, produced by bees after they collect "honeydew" (secretions of insects belonging to the genus, Rhynchota), which pierce plant cells, ingest plant sap and then secrete it again; (iii) monofloral honey, in which the bees forage predominantly on one type of plant and which is named according to the plant; for instance, coffee("Coffeeabyssinica) , Bisana("Crotonmacrostachyus"), Geteme("Scheffleraabbyssinica"); (iv) multifloral honey (also known as polyfloral) that has several botanical sources, none of which is predominant, e.g., meadow blossom honey and forest honey [2].

Honey is a concentrated aqueous solution of different carbohydrates. The major components of honey and the most dominant are the monosaccharides fructose and glucose (accounting for 85 to 95\%); the actual proportion of glucose to fructose in any particular honey depends largely on the source of the nectar. The average ratio of 
fructose to glucose is $1.2: 1$. The amount of glucose in honey is usually at a supersaturated level at normal temperatures [3]. The concentration of fructose and glucose, as well as the ratio between them, is useful indicators for the classification of monofloral honeys [4]. In almost all types of honey, fructose is the carbohydrate in greatest proportion, except in some honeys such as rape (Brassica napus) and dandelion (Taraxacum officinale); where in the fraction of glucose may be higher than the fractions of fructose, and consequently these honeys, generally, have a rapid crystallization [5]. Numerous studies have pointed that many of the Ethiopian honey contains sugar, proteins, vitamins, minerals, enzymes, polyphenols and flavonoids important for the proper maintenance of human health. Because of this unique and complex nature, honey is proved to be useful in the treatment of burns, wounds, skin ulcers, in the treatment of external eye diseases as an antioxidant and as antimicrobial [6]. Because of its unique flavor, high nutritional value and limited availability, the price of natural bee honey is relatively much higher than that of other sweeteners. Due to this reason, honey is vulnerable to adulteration with cheaper sweeteners. Adulteration is the act of adding adulterants to honey for boosting their cash income by increasing its volume or due to carelessness and lack of proper hygienic condition during processing, storing, transportation and marketing. The common adulterants of honey are; Sugar syrup, molasses, corn syrup, high fructose or maltose syrup and sweet potato. These Adulterants changes the natural identity of honey. This leads or follows a very serious impact on producers/farmers, processors or anufacturers/enterprises and government like lack of acceptance in the market due to disrupting its originality and also for the consumers that cause serious diseases like, overweight, obesity and diabetes mallets. For this reason, it requires certain standards and norms that guarantee its identity and quality. The authenticity of honey is defined internationally by the Codex Alimentarius, which establishes the identity and the essential quality requirements of honey intended for direct human consumption. These standards are applied to honey produced by bees and cover all styles of honey presentations, which are processed and ultimately intended for human consumption [7].

The purpose of these laws is to establish the identity and minimum quality requirements for honey. Among other factors, these regulations take into account the sensory and physicochemical properties of honey by setting the color and the minimum or maximum amount related to maturity, purity and deterioration parameters for honeys. With respect to maturity, the regulation evaluates sugar content and moisture; for purity, it analyses ash content, electrical conductivity and insoluble solids in water. Although several legislations establish identity and quality requirements, honey composition and quality varies geographically as well as botanical origin because of climatic factors and unreliable honey merchants who adulterate pristine honeys for boosting the volume by adding other cheaper sweeteners [8]. The adulterated samples may have free circulation in the internal market and access to the external market and may cause serious socio-economic problems [8]. Studies on honey in Ethiopia have focused on nutritional compositions and reported great varieties of botanical origins of honey sample $[9,10]$. Very limited information is available in scientific literature regarding adulteration, particularly on the currently selected branded varieties. This study focuses on authentication and determination of adulteration in honey samples of the selected botanical origins (Coffee, Bisana and Geteme) from selected branded honey production areas (Bonga, Bore and Yirgachefe) in Ethiopia.

\section{MATERIALS AND METHODS}

\subsection{Description of the Study area and Study design}

The research was conducted in three well known honey production areas in Ethiopia, namely Bore, Bonga and Yirgachefe. Bore is one of the woredas in the Oromia region of Ethiopia, part of Guji zone is bordered on the south by Anasora, on the west by Uraga, and on the north and east by SNNPR. The latitude and longitude of $7^{0} 52^{\prime} 0$ ' $\mathrm{N} / 37^{0} 1^{\prime} 60$ ' with an elevation of $1800-2900$ meters above sea level, and it is $384 \mathrm{Km}$ from the capital city, Addis Ababa, and $333 \mathrm{Km}$ from its regional town (Adama); Bonga is south-western Ethiopia and located south west of Jimma in the Keffa zone of the SNNPR upon a hill in the upper Bata valley, it has a latitude and longitude of $7^{0} 16^{\prime} \mathrm{N} 36^{0} 14^{\prime} \mathrm{E} / 7.267^{\circ} \mathrm{N} 36.233^{\circ} \mathrm{E}$ with an elevation of 1,714 meters above sea level, its weathering condition is a temperature of $24^{0} \mathrm{c}$, wind $\mathrm{S}$ at $5 \mathrm{Km} / \mathrm{hr}$, humidity $62 \%$ and it is $449 \mathrm{Km}$ from the capital city, Addis Ababa and $571 \mathrm{Km}$ from its regional town (Hawassa); and the remaining, Yirgachefe is southern region of Ethiopia, located in the Gedeo zone of the SNNPR, its latitude and longitude of $6^{0} 10^{\prime} \mathrm{N} 38^{0} 12^{\prime} \mathrm{E} / 6.167^{\circ} \mathrm{N}$ $38.200^{\circ} \mathrm{E} / 6.167 ; 38.200$ with an elevation between 1,880 and 1,919 meters above sea level, the weathering condition is a temperature of $22-23{ }^{\circ} \mathrm{c}$, wind SE at $5 \mathrm{Km} / \mathrm{hr}$, humidity and it is $394 \mathrm{Km}$ from the capital city, Addis Ababa and $118 \mathrm{Km}$ from its regional town (Hawassa).

\subsection{Sample collection}

Different botanical samples were collected from selected sampling sites. The samples were taken from these places in different months depending on floral seasons. A total of thirty honey samples were collected from different bee farmers and merchants in Bonga, Bore and Yirgachefe. The selection was based on origins of accepted honey brands and the agro-climatic condition supporting the botanical basis of selection. Thus purposive sampling technique was implemented. Since the honey samples collected from different places should have the same 
botanical basis, samples were specifically collected from places that support the growth of the suggested forage trees coffee ("Coffee abyssinica), Bisana ("Crotonma crostachyus") and Geteme ("Schefflera abbyssinica"). The samples were collected by using clean plastic tire. The plastic tires containing the samples were closed to avoid moisture exchange.

\subsubsection{Outline of sample collection schemes}

\subsubsection{Geographical and Botanical origin of pristine samples}

A: "Bore" Honey (3 samples (1 kg each) from different bee farmers): A total of 6 samples (3 Geteme honey samples (1 kg each) from different bee farmers, 3 Bisana honey samples (1 kg each) from different bee farmers) were collected. Honeys from these sites were coded as BoreG (BoreG1, BoreG2 and BoreG3), BoreB (BoreB1, BoreB2 and BoreB3) to mean Bore Geteme honey and Bore Bisana honey, respectively.

B: "Bonga" Honey (3 samples (1 kg each) from different bee farmers). A total of 9 samples (3 coffee honey samples $(1 \mathrm{~kg}$ each) from different bee farmers, 3 Geteme honey samples $(1 \mathrm{~kg}$ each) from different bee farmers, 3 Bisana honey samples (1 kg each) from different bee farmers) were collected. Honeys from these sites were coded as BongaC (BongaC1, BongaC2, and BongaC3), BongaG (BongaG1, BongaG2 and BongaG3), BongaB (BongaB1, BongaB2, Bonga B3) to mean Bonga coffee, BongaGeteme and Bore Bisana honey, respectively.

C: "Yirgachefe"Honey (3 samples ( $1 \mathrm{~kg}$ each) from different bee farmers). A total of 6 samples (3 coffee honey samples $(1 \mathrm{~kg}$ each) from different bee farmers, 3 Bisana honey samples (1 kg each) from different bee farmers) were collected. Honeys from these sites were coded as Y/ChefeC (Y/ChefeC1, Y/ChefeC2, and Y/ChefeC3) and Y/ChefeB (Y/ChefeB1, Y/ChefeB2, and Y/ChefeB3) to mean Y/Chefe coffee, Y/ChefeBisana honey, respectively.

\subsubsection{Commercial Samples (9 samples)}

A total of 9 samples [ 3 coffee honey samples ( $1 \mathrm{~kg}$ each) of different 3 Bonga honey merchants, 3 Geteme honey samples ( $1 \mathrm{~kg}$ each) of different 3 Bonga honey merchants and 3 Geteme honey samples $(1 \mathrm{~kg}$ each) of different 3 Bore honey merchants] were collected. Honeys from these sites were coded as BoreC(BoreCG and BoreCB), BongaC (BongaCC and BongaCG).

\subsubsection{Sample labeling}

During the honey labeling, the names of the products were complemented with the data regarding its floral or herbal origin when the product comes entirely or mainly from the indicated plant source and the data were regarded to its regional, territorial, or topographical origin .

\subsection{Sample Handling}

The honey samples were transported to HU chemistry laboratory and stored in a dark cupboard at room temperature. Physicochemical properties (moisture content, ash content, $\mathrm{pH}$, total solid content and some samples of ash content) were analyzed immediately at HU chemistry laboratory. Finally quantitative and qualitative analysis of selected sugars (fructose, glucose, sucrose) was carried out at Ethiopian Conformity Assessment Enterprise.

\subsection{Chemicals and reagents}

Fructose, Glucose and Sucrose (Buck Scientific calibration standards, USA) were used for preparation of stock standard and working standard solutions to plot calibration graphs, Methanol HPLC grade (Nice, India) was used for dissolving purpose as a solvent, Acetonitrile HPLC grade (analytical reagent, England), used for preparing mobile phase solution, Deionized water used for all solution preparation, mix solution of Acetonitrile with Water in the ratio of 70:30 (Acetonitrile: Water) used for mobile phase and solvent mixture (Methanol: Water, 25:75) used as a solvent purpose for all solution preparations of HPLC analysis.

\subsection{Instrument and Apparatus}

In this work, Higher Performance Liquid Chromatographic Technique (Agilent technologies, 1260 infinity series, Japan) consisting of pump, sample applicator, temperature regulated RID thermo stated at $30^{\circ} \mathrm{c}$, temperature regulated column: a carbohydrate $4.6^{*} 150 \mathrm{~mm}, 5 \mu$ particle size were used for quantitative and qualitative determination of sugar contents in honey samples by plotting calibration graph of sugar standards (fructose, glucose, and sucrose) and qualitative determination. Syringe filters (Shimadzu, Japan), were used for filtering samples and standards before transferring into sample vials. Sample vials (Shimazdu, Japan), were used for containing samples and standards for HPLC analysis. Refrigerator (Hitachi, Germany) was used to keep the prepared solution standards. Digital analytical beam balance (ADAM, Model AFP-110L, England) with $120 \mathrm{~g}$ loading capacity and \pm 0.0001 precision was used for weighing all the stock sugar standards and samples. Drying oven (Digit heat, J. P. Selecta, Germany) was also be used for drying the samples placed on a crucible. Ultrasonic bath (Shimazdu, Japan), was used for dissolving purpose when some solutes were not dissolved easily. Furnace (Digit heat, J. P. Selecta, Germany) used for heating the crucibles containing the sample. Crucibles (Duran, Germany) were used for containing samples when determination of ash and moisture content performed. Desiccator (ADAM, England) was used for cooling the heated samples. pH meter (Hitachi, Germany) was used for measuring $\mathrm{pH}$ of the collected samples. Measuring cylinders, volumetric flasks (Duran, Germany), beakers and pipettes (Pyrex, England), were used for measuring different volumes of sample solution, reagents and sugar 
standard solutions.

\subsection{Physicochemical Analysis \\ 2.5.1. Determination of $\mathbf{p H}$}

For determination of $\mathrm{pH}$, the method of AOAC [11] was adopted and digital $\mathrm{pH}$ meter was used. The $\mathrm{pH}$ meter was calibrated with buffers at $\mathrm{pH} \mathrm{4,7}$ and 10. Sample solutions were taken in the beaker and then insert the $\mathrm{pH}$ meter. When the first reading was completed, the electrode was rinsed with distilled water and dried-up with tissue paper. Similarly, as a continue series, all other samples were determined accordingly.

\subsubsection{Determination of moisture content}

The moisture content was determined according to AOAC [12]. In this regard, the sample materials were taken in a flat-bottom dish (pre-weighed) and kept overnight in an oven at $100-110^{\circ} \mathrm{C}$ and weighed. The loss in weight was regarded as a measure of moisture content which was be calculated by the following formula:

\subsubsection{Determination of ash content}

$$
\text { Moisture }(\%)=\frac{\text { Weight of fresh sample }- \text { Weight of dried sample }}{\text { Weight of fresh sample }} \times 100
$$

For the determination of ash content, the method of AOAC [11] was followed. According to the method, $5 \mathrm{~g}$ of each sample was weighed in a crucible. The crucibles containing the sample were heated in a furnace for about 3 to $5 \mathrm{~h}$ at $500^{\circ} \mathrm{C}$, after that be cooled in desiccators and weighed. To ensure completion of ashing, reheated again in the furnace for half an hour more, cooled and weighed. Repetition was continued consequently until the weight became constant (ash became white or grayish white). Weight of ash was calculated by the following formula:

\subsubsection{Determination of total solids}

$$
\operatorname{Ash}(\%)=\frac{\text { Weight of sample after ashing }}{\text { Weight of fresh sample taken }} \times 100
$$

The percentage total solid of each sample were determined by using the following formula:

Total solids $(\%)=100-$ Moisture content

\subsection{Preparation of solutions}

Firstly, $100 \mathrm{~mL}$ each of $20 \%$ stock standard solution of individual sugars was prepared in a solvent mixture of (methanol: water, 25:75) with the help of ultrasonic bath [13]. Each of these solutions is regarded as standard (1). For the preparation of 5\% fructose, $5 \%$ glucose and $1 \%$ sucrose mixture standard (standard 2 ), $25 \mathrm{~mL}$ fructose, $25 \mathrm{~mL}$ glucose and $5 \mathrm{~mL}$ sucrose were pipetted from the previously prepared (standard 1) into $100 \mathrm{~mL}$ of volumetric flask, mixed and made up to volume with the solvent mixture. Then, working standards of $0.5 \%, 1 \%$, $1.5 \%, 2 \%$ and $3 \%$ of glucose and fructose and $0.1 \%, 0.2 \%, 0.3 \%, 0.4 \%$ and $0.6 \%$ of sucrose were prepared from (standard 2) by serial dilution.

\subsection{Pretreatment and Preparation of honey samples}

The samples were first pretreated by pouring in to closed container and placed in ultrasonic bath without submerging and heated for 30 minutes at $50{ }^{\circ} \mathrm{C}$ to obtain a liquid sample. Solid particles were removed by filtration [14]. Then, the sample solutions were prepared by weighing $5 \mathrm{~g}$ of homogenized honey sample into $100 \mathrm{~mL}$ of volumetric flask and dissolved with $40 \mathrm{~mL}$ of solvent mixture (methanol: water, 25:75). Then, the sample solutions were stirred using glass rods to dissolve thoroughly. After that, the solutions were transferred into $100 \mathrm{~mL}$ volumetric flask, and made up to mark with solvent mixture. Prior to injection, all sample solutions were collected into sample vials by filtering through $0.45-\mu \mathrm{m}$ filters about $1.5 \mathrm{~mL}$ to remove small particles. Finally, the sample solutions were used for HPLC analysis to determine sugar content in honey samples [13].

\subsection{HPLC method parameters}

Before running the standards and samples, all parameters of the instrument were optimized under specific conditions. A carbohydrate $4.6^{*} 150 \mathrm{~mm}, 5 \mu$ particle size HPLC column was used to obtain separation of fructose, glucose and sucrose. The optimum mobile phase was found to be an acetonitrile: water mix in the ratio of $70 \%: 30 \%$ and the selected detector were RID. The first step in the analysis was optimizing the mobile phase, flow rate $(0.5$ $\mathrm{mL} / \mathrm{min})$, retention time $\left(20 \mathrm{~min}\right.$, injection volume $(10 \mu \mathrm{L})$, column and detector temperature $\left(30^{\circ} \mathrm{c}\right)$ and sequence of a sample. The detection of these sugars in the suggested samples was based on enhancement in the corresponding peaks as a result of presence and no change as a result of absence. The optimized conditions of the instrument are shown in Table 2.1. 
Table 2.1: Optimized conditions of HPLC instrument parameter

\begin{tabular}{|l|l|}
\hline Column: & Carbohydrate $4.6 * 150 \mathrm{~mm}, 5 \mu$ particle size \\
\hline Mobile phase: & Acetonitrile $:$ water $(70: 30)$ \\
\hline Solvent program: & Methanol:water $(25: 75)$ \\
\hline Analysis Time $(\mathrm{min}):$ & $20 \mathrm{~min}$ \\
\hline Flow rate $(\mathrm{ml} / \mathrm{min}):$ & $0.5 \mathrm{~mL} / \mathrm{min}$ \\
\hline Oven Temp: & $30^{\circ} \mathrm{c}$ \\
\hline Detection: & Refractive index detector \\
\hline Injection Volume: & $10 \mu \mathrm{L}$ \\
\hline Sampling rate: & $0.0072 \min (0.432 \mathrm{sec})$ \\
\hline
\end{tabular}

\subsection{Data Analysis}

The collected data were coded and tabulated for analysis. The data were analyzed using Microsoft Excel 2007 to get the mean and standard deviation of all the samples and the statistical tests of significance were performed by using one way ANOVA and t-test. These were applied to determine whether there was any statistical difference between the mean concentrations of the sugars in Geteme, Bisana and Coffee honey samples. The obtained data and Honey quality parameters were analyzed by a computer program using Origin 8 version.

\section{RESULTS AND DISCUSSION}

\subsection{Physicochemical analysis of honey samples}

Determination of honey quality and adulteration requires carefully established parameters that can be quantified. Codex Alimentarius established the identity and minimum quality requirements for honey intended for direct human consumption. Among other factors, the physicochemical parameters ( $\mathrm{pH}$, ash content, total solids, moisture content, electrical conductivity, etc.) and sugar composition (fructose, glucose, sucrose, maltose, etc.) of honey are considered.

Moisture content is an important quality parameter and its significance in honey derives from the fact that there is a relationship between honey water content and yeast count. Generally, at $17.0 \mathrm{~g} / 100 \mathrm{~g}$ moisture (humidity) there is very minimal fermentation danger due to very low yeast count. Thus, honey having high water content is more likely to ferment. A maximum value of $20.0 \mathrm{~g} / 100 \mathrm{~g}$ was established by the Codex Alimentarius Commission and EU Commission as the international standard for honey moisture contents. The ash content of honey is also a parameter that is used in determining the floral origin of honeys and index of possible environmental pollution and a potential indicator of geographical origin of honey. In addition to this, ash contents of honeys represent their mineral and trace element contents. In a similar manner, a maximum value of $0.6 \%$ was established by the Codex Alimentarius Commission and EU Commission as the international standard for honey ash contents. The $\mathrm{pH}$ of honey is commonly between 3.2 and 4.5. This is relatively acidic; $\mathrm{pH}$ level prevents the growth of many bacteria. The presented values correspond to the mean of three measurements in each case. The results of physicochemical analyses (moisture content, total solids, ash content and $\mathrm{pH}$ ) of honey samples of different geographical and botanical origins are summarized in Table 3.1.

The moisture content of all the honey samples considered in this study ranged from $17.42 \pm 1.46$ to $25.07 \pm$ $0.75 \%$. The moisture content of all the honey samples from Keffa were above the required standards (more than $20 \%$ ) of the European Regulations of Quality whereas that of Bore and Yirgachefe were within the specified range [15]. This value is related to honey quality and high moisture content can lead to fermentation during storage, resulting in production of ethyl alcohol and carbon dioxide. The dry matter (total solids) of coffee honey samples ranged from $74.93 \pm 0.77$ to $83.49 \pm 1.61 \%$. According to [16], the largest portion of the total solid matter in honey consists of sugars, which represent an average of $73 \%$ of the honey samples. Since the total sugar content of honey samples is also an indicator of honey quality, the total solids also represent honey quality. 
Table 3.1: Results (Mean \pm SD) of physicochemical analyses

\begin{tabular}{|c|c|c|c|c|}
\hline Samples & $\begin{array}{c}\text { Moisture } \\
(\mathbf{\%})\end{array}$ & Total solids (\%) & Ash (\%) & pH \\
\hline Bore Geteme Farmer Honey (BGFH) & $19.75 \pm 1.37$ & $80.25 \pm 1.40$ & $0.77 \pm 0.30$ & $3.60 \pm 0.67$ \\
\hline Bore Geteme Commercial Honey (BGCH) & $17.42 \pm 1.46$ & $82.58 \pm 1.50$ & $0.65 \pm 0.47$ & $3.63 \pm 0.83$ \\
\hline Bore Bisana Farmer Honey (BBFH) & $18.65 \pm 1.78$ & $81.35 \pm 1.81$ & $0.57 \pm 0.63$ & $3.75 \pm 0.92$ \\
\hline KeffaBisana Farmer Honey (KBFH) & $21.03 \pm 0.92$ & $78.97 \pm 0.98$ & $0.38 \pm 0.15$ & $3.78 \pm 0.56$ \\
\hline KeffaGeteme Farmer Honey (KGFH) & $20.84 \pm 0.87$ & $79.16 \pm 0.94$ & $0.49 \pm 0.29$ & $3.69 \pm 0.78$ \\
\hline KeffaGeteme Commercial Honey (KGCH) & $24.62 \pm 1.27$ & $75.38 \pm 1.31$ & $0.56 \pm 0.23$ & $3.69 \pm 0.35$ \\
\hline Kefa Coffee Commercial Honey (KCCH) & $25.07 \pm 0.75$ & $74.93 \pm 0.77$ & $0.35 \pm 0.12$ & $3.81 \pm 0.74$ \\
\hline Kefa Coffee Farmer Honey (KCFH) & $22.19 \pm 1.65$ & $77.81 \pm 1.72$ & $0.41 \pm 0.17$ & $3.79 \pm 0.68$ \\
\hline Y/Chefe Coffee Farmer Honey (Y/CCFH) & $16.51 \pm 0.55$ & $83.49 \pm 1.61$ & $0.73 \pm 1.68$ & $3.91 \pm 0.41$ \\
\hline Y/ChefeBisana Farmer Honey(Y/CBFH) & $17.93 \pm 0.73$ & $82.07 \pm 1.45$ & $0.64 \pm 2.42$ & $3.92 \pm 0.59$ \\
\hline Over all mean \pm SD & $\mathbf{2 0 . 4 0 \pm 1 . 1 4}$ & $\mathbf{7 9 . 6 0} \pm \mathbf{1 . 3 5}$ & $\mathbf{0 . 5 6} \pm \mathbf{0 . 6 5}$ & $\mathbf{3 . 7 6} \pm \mathbf{0 . 6 5}$ \\
\hline
\end{tabular}

Source: Collected honey samples (laboratory analysis result) Values are presented as mean $\pm \mathrm{SD}$

The ash content of coffee honey samples ranged from $0.35 \pm 0.12$ to $0.77 \pm 0.30 \%$. Although a standard value for ash content is not specified by the Codex Alimentarius Committee on Sugars, most studies reported the average ash content in honey as $0.17 \%(\mathrm{w} / \mathrm{w})$, ranging between $0.02 \%$ to $1.03 \%(\mathrm{w} / \mathrm{w})$ [17]. Compared to the reports of the previous studies, thus, a higher ash contents were recorded in the current samples. The higher mineral content of the current samples is, however, consistent with stronger flavor of the samples that make them attractive for consumption $[18,19]$.

The $\mathrm{pH}$ values of all the studied honey samples ranged from $3.60 \pm 0.67$ to $3.92 \pm 0.59$. In addition, there were no significant differences among the $\mathrm{pH}$ values of the samples of different floral and geographical origins considered in this study. The observed low $\mathrm{pH}$ of the samples suggests their good quality in terms of vitamin content [20]. Although the Regulatory Committees has not yet established a standard for this parameter, a $\mathrm{pH}$ level between 3.2 and 4.5 are common in pure honey and the natural acidity of the honey inhibit the growth of microorganisms, as the optimum $\mathrm{pH}$ for most organisms is between 7.2 and 7.4 [21]. The $\mathrm{pH}$ is also indicative of other authenticity parameters to verify adulterations and presence of organic acids in equilibrium with lactone, internal esters and some inorganic ions such as phosphates, sulfates and chlorides [22]. For instance, the addition of high fructose corn syrup in honey could result in a significant increase of in $\mathrm{pH}$ values compared to pure honey [23]. In general, most of the physicochemical parameters in the honeys considered in this study were in accordance with the international standards established by [15] and suggest good quality of the honey samples.

\subsection{Determination of Sugar Composition}

The concentration of reducing sugars fructose and glucose, as well as the ratio between them, are useful indicators for the authentication of honeys [4]. According to the Codex Alimentarius Committee standards on Sugars, the minimum amount of reducing sugars is $60 \mathrm{~g} / 100 \mathrm{~g}$ for floral honey [8]. Besides the reducing sugars analysis, the amount of sucrose is a very important parameter in evaluating the honeys' maturity. The sucrose content in honey is analyzed with the purpose of identifying any improper manipulation of honey, and high levels may indicate a variety of adulterations, such as adding cheap sweeteners like cane sugar or refined beet sugar; early harvest, indicating that the sucrose was not completely transformed into glucose and fructose or prolonged artificial feeding of honeybees with sucrose syrups, resulting in high commercial profits [24, 25].

In this study, the fructose, glucose and sucrose content of different honey samples collected from selected areas of Ethiopia were analyzed by HPLC-RID instrument to determine adulteration by sugar syrups but chromatograms of these sugar standards and calibration plots were examined before sample analysis. The calibration graphs were used to determine the concentration of fructose, glucose and sucrose in all different analyzed honey samples as shown below in Figure 3.1. The average peak areas and retention times were used for plotting for the calibration graphs of all three sugar standards. Injections of all standards were done in triplicate manner using standards concentrations of $0.5,1.0,1.50,2.0,3.0,5.0$ for fructose and glucose and $0.1,0.2,0.3,0.4$, 0.6 , and $1.0 \mathrm{Amt}[\%]$ for sucrose under specified conditions $\left[\left(\mathrm{T}=30^{\circ} \mathrm{c}\right.\right.$, flow rate $=0.5 \mathrm{~mL} / \mathrm{min}, \mathrm{RT}=20 \mathrm{~min}$, mobile phase $=70: 30$ (acetonitlrie:water)].

As shown in the above Figure 3.1, $\mathrm{R}^{2}$ values of fructose, glucose and sucrose are 0.99997, 0.99869 and 0.99517 respectively. The calibration curves of the three sugars are indicated in Figure 3.1 with linear regression equations of $1.48921 * 10^{6}+49573.75,1.52471 * 10^{6}+119548.75$ and $1.58285^{*} 10^{6}-10933.5652$ for fructose, glucose and sucrose, respectively with $\mathrm{R}^{2}$ values above $99 \%$ in all cases. 


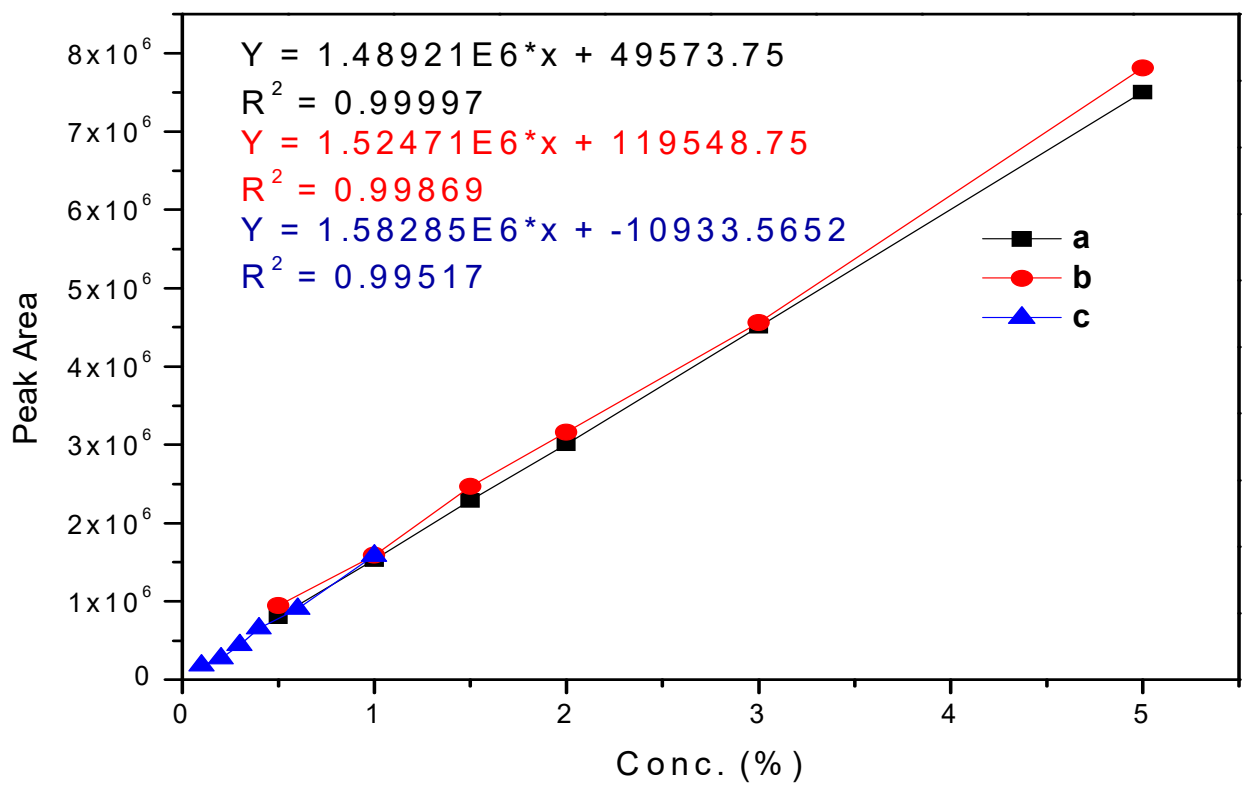

Figure 3.1: (a) Indicates calibration graph of fructose in concentration range of $(0.5-5 \%)$;(b) indicates calibration graph of glucose in concentration range of $(0.5-5 \%)$ and $(\mathbf{c})$ indicates calibration graph of sucrose in concentration range of $(0.1-1 \%)$.

The sugar compositions of each sample were determined using the above calibration curves and results are summarized in Table 3.2. The fructose content of most of the current samples was consistent within a standard limit (about 38.5\%) but those of BBFH (32.43), $\mathrm{KCCH} \mathrm{(31.57),} \mathrm{KCFH} \mathrm{(47.50),} \mathrm{and} \mathrm{Y/CCFH} \mathrm{(28.70)} \mathrm{were}$ markedly different from the standard. Similarly, the glucose content of most of the samples was not significantly different from the standard. But KCFH (22.97), KCCH (23.03), and BBFH (24.50) had glucose contents markedly different from the standard. The Fructose/Glucose ratio of the honeys studied varied between 0.97 and 2.07 with most of the values reasonably in agreement with the standard and most of previous investigators [13], who reported $\mathrm{F} / \mathrm{G}$ average ratio around 1.2. The $\mathrm{KGCH}(1.49), \mathrm{KCFH}(2.07)$, and $\mathrm{Y} / \mathrm{CCFH}(0.97)$ had the $\mathrm{F} / \mathrm{G}$ ratios significantly different from the standard (1.22-1.30).

Table 3.2: Results of average sugar composition of honey samples

\begin{tabular}{|c|c|c|c|c|c|c|c|}
\hline $\begin{array}{c}\text { Sample } \\
\text { code }\end{array}$ & $\begin{array}{c}\text { Fructose } \\
\text { content }\end{array}$ & $\begin{array}{c}\text { Glucose } \\
\text { content }\end{array}$ & $\begin{array}{c}\text { Fructose }+ \\
\text { glucose }\end{array}$ & $\begin{array}{c}\text { Fructose/ } \\
\text { glucose ratio }\end{array}$ & $\begin{array}{c}\text { Sucrose } \\
\text { content }\end{array}$ & $\begin{array}{c}\text { Total } \\
\text { sugar }\end{array}$ & $\begin{array}{c}\text { Glucose/ } \\
\text { moisture ratio }\end{array}$ \\
\hline BGFH & 41.73 & 34.87 & 76.60 & 1.196731 & 0.68 & 77.28 & 1.76557 \\
\hline BGCH & 42.43 & 35.97 & 78.40 & 1.179594 & 0.75 & 79.15 & 2.064868 \\
\hline BBFH & 32.43 & 24.50 & 56.93 & 1.323673 & 0.34 & 57.27 & 1.313673 \\
\hline KBFH & 35.27 & 29.03 & 64.30 & 1.21495 & 0.00 & 64.3 & 1.380409 \\
\hline KGFH & 41.63 & 32.17 & 73.80 & 1.294063 & 0.00 & 73.8 & 1.543666 \\
\hline KGCH & 44.10 & 29.57 & 73.67 & 1.491376 & 0.40 & 74.07 & 1.201056 \\
\hline KCCH & 31.57 & 23.03 & 54.60 & 1.370821 & 0.69 & 55.29 & 0.918628 \\
\hline KCFH & 47.50 & 22.97 & 70.47 & 2.067915 & 1.03 & 71.5 & 1.035151 \\
\hline Y/CCFH & 28.70 & 29.60 & 58.30 & 0.969595 & 0.81 & 59.11 & 1.792853 \\
\hline Y/CBFH & 33.00 & 30.63 & 63.63 & 1.077375 & 0.39 & 64.02 & 1.70831 \\
\hline SBGFH & 72.13 & 65.40 & 137.53 & 1.102905 & 5.11 & 142.64 & \\
\hline SKGFH & 71.27 & 61.37 & 132.64 & 1.161316 & 5.41 & 138.05 & \\
\hline SBGCH & 72.67 & 65.87 & 138.54 & 1.10323364 & 5.73 & 144.27 & \\
\hline
\end{tabular}

Source: Collected honey samples (laboratory analysis result)

Considering the total content of fructose and glucose, most of the analyzed samples had the values consistent with the standard $\geq 60 \mathrm{~g} / 100 \mathrm{~g}$ even though the sum content of fructose and glucose of the three samples BBFH (56.93), $\mathrm{KCCH} \mathrm{(54.60),} \mathrm{and} \mathrm{Y/CCFH} \mathrm{(58.30)} \mathrm{fall} \mathrm{below} \mathrm{the} \mathrm{international} \mathrm{standard} \mathrm{for} \mathrm{honey} \mathrm{established} \mathrm{by} \mathrm{Codex}$ Alimentarius Commission. From the above analysis, it can be concluded that the BBFH, KCCH and Y/CCFH do not fulfill most of the quality requirements set for honey established by Codex Alimentarius Commission [8] and are of less quality. In addition to the determination of fructose and glucose content in honey samples, the 
international norm established by the Codex Alimentarius Commission requires that a good quality honey should not contain more than $5 \mathrm{~g} / 100 \mathrm{~g}$ sucrose.

The sucrose content in the current samples ranged between 0.00 and $1.03 \mathrm{~g} / 100 \mathrm{~g}$. Sucrose is an important sugar from the legislative point of view. The sucrose content in honeys can be increased if the beekeeper has overfed the bees with sugar during spring [26]. Moreover, a high content of this sugar means an early harvest of honey [27]. During honey storage the sucrose level can decrease by action of the invertase [26] and is indicative of honey maturity. The data from current study of sucrose content are in general consistent with the values reported elsewhere [28]. Since the sucrose content is below the limit, adulteration is not detected in all the samples considered in this study. This is also consistent with the wider acceptance of these honeys in the country as free from adulteration and of high quality by the consumers in those studied areas.

Total sugar concentration is the other parameter to assess honey quality. The total sugar content of the samples considered in the current study showed a wide range, varying between 55.29 and 79.15, which agrees with data reported by other investigators [29]. The glucose: moisture content ratios are more specific and have served as indicator for predicting honey crystallization and hence honey quality [30]. When the glucose/moisture ratio is under 1.7, a slowly crystallizing honey is produced. The glucose/moisture ratio of the studied samples varied between $0.92(\mathrm{KCCH})$ and $2.06(\mathrm{BGCH})$. All honeys except, $\mathrm{KCCH}$ analyzed in this study had a value of this ratio higher than 1.7, which is consistent with the standards. The overall mean values of all analyzed honey samples in different tested characteristics of the study areas compared to National and International standard are summarized in Table 3.3. As shown in Table 3.3, the quality levels of the parameters in all the analyzed honey samples are consistent with World, FAO/WHO and National standards. There was no significant difference (p>0.05) in the mean values of fructose plus glucose content, the sucrose content, the moisture content, total ash contents and $\mathrm{pH}$ value between the analyzed honey samples and standards.

Table 3.3: Comparison of studied honey quality against National and International Standards

\begin{tabular}{|l|l|l|l|l|}
\hline \multirow{2}{*}{ Characteristic tested } & \multicolumn{2}{|l|}{ Standards } & Analyzed sample \\
\cline { 2 - 4 } & World & FAO/WHO & \multicolumn{1}{|c|}{ National } & \\
\hline Moisture content, \% by mass & $18-23$ & $21-23$ & 21 max. & 20.40 \\
\hline Total ash, \% by mass & $0.25-1$ & $0.6-1$ & $0.6 \max$. & 0.56 \\
\hline Fructose + Glucose & $60-70$ & 65 min. & 65 min. & 67.07 \\
\hline Sucrose content \% by mass & $3-10$ & $5-10$ & $5 \max$. & 0.51 \\
\hline pH & $3.2-4.5$ & & & 3.76 \\
\hline
\end{tabular}

Source: Quality and Standards Authority of Ethiopia (2005)

\subsection{Comparison of sugar contents of different geographical origins}

The chemical analysis of honey with respect to the botanical and geographical origins can improve the reliance of customers on certified regional products. The geographical origin is a criterion of quality with certified description of origin. Therefore, the geographical categorization of honeys can raise its commercial value, and contribute to the micro economy of the region. The comparison of sugar content of honey samples of different locations are summarized in Table 3.4. As shown in the above Table 3.4, the significant differences $(\mathrm{P}<0.05)$ in the fructose, glucose and (fructose+glucose) were observed in samples from Bore, Keffa and Yirgachefe areas. But, no significant difference $(\mathrm{P}>0.05)$ were observed in their (fructose /glucose) and sucrose between Bore, Keffa and Yirgachefe geographical areas. Similarly, the fructose and glucose content were significantly different, $(\mathrm{P}<0.05)$ in Bore and Keffa geographical areas honey samples but no significance difference in Yirgachefe honey samples. The average fructose content of Bore and Keffa are closer to standard value $(38.5 \mathrm{~g} / 100 \mathrm{~g})$ set by Codex Alimentarius Commission. Samples from Yirgachefe had average fructose content of 30.85 \pm 3.04 ; which is significantly different from the standard.

Table 3.4: Comparison of sugar content of honey samples from different geographical areas

\begin{tabular}{|l|l|l|l|}
\hline Parameter & Bore & Keffa & Yirgachefe \\
\hline Fructose $(\mathrm{g} / 100 \mathrm{~g})$ & $38.87 \pm 5.58$ & $40.01 \pm 6.5$ & $30.85 \pm 3.04$ \\
\hline Glucose $(\mathrm{g} / 100 \mathrm{~g})$ & $31.78 \pm 6.33$ & $27.35 \pm 4.15$ & $30.12 \pm 0.73$ \\
\hline Sucrose $(\mathrm{g} / \mathrm{100 \textrm {g } )}$ & $0.59 \pm 0.22$ & $0.43 \pm 0.45$ & $0.60 \pm 0.29$ \\
\hline Fructose + Glucose & 70.64 & 67.37 & 60.97 \\
\hline Fructose / Glucose & 1.22 & 1.46 & 1.02 \\
\hline
\end{tabular}

Source: Collected honey samples (laboratory analysis result) Values are presented as mean $\pm \mathrm{SD}$

In terms of average glucose content, the Bore and Yirgachefe samples had values closer to the standard $(31.5 \mathrm{~g} / 100 \mathrm{~g})$ while, the Keffa samples showed a significantly different average glucose content than the standard. The mean values of fructose to glucose ratio of Bore, Keffa and Yirgachefeare1.22, 1.46 and 1.02 respectively. These value inferred that, there were no significant difference $(p>0.05)$ between these three places in their $F / G$ ratio. The average sum of fructose and glucose of Bore, Keffa and Yirgachefe are 70.64, 67.37 and 60.97 
respectively. This observation shows that, although all studied areas corresponding to the limit required by the international norms; i.e., $\geq 60 \mathrm{~g} / 100 \mathrm{~g}$ bore honey samples are the most authentic and there were significant difference $(\mathrm{p}<0.05)$ between those geographical areas.

\subsection{Comparison of sugar contents of different botanical origins}

For the determination of the botanical origin of honey, a criterion for the determination of unifloral as well as polyfloral origin needs to be developed. However, it is very complex to identify consistent chemical markers for the differentiation of honey of different floral sources due to their chemical composition which is influenced by a number of other factors, including geographic origin, bee species, collection season, mode of storage. Hence, different markers have been reported for honey of the same floral origin. Additionally, sample preparation and analytical techniques also contribute to results for chemical analyses of honey constituents. The sugar contents of different floral origins are shown below in Table 3.5.

Table 3.5 shows that, the average fructose content of Geteme, Bisana and Coffee floral origin honey samples are $42.48 \pm 1.14,33.57 \pm 1.49926$ and $35.92 \pm 10.13$ respectively, in a similar way the average glucose content of these floral origins are 33.14 $\pm 2.87,28.06 \pm 3.18143$ and $25.20 \pm 3.81$ respectively. There were significant difference $(\mathrm{p}<0.05)$ between Geteme, Bisana and Coffee in their mean values of the both the fructose and glucose contents of the honey samples. Those values indicates that, in all three floral origins fructose content is higher than glucose content and the Geteme honey samples have higher fructose and glucose content than Bisana and Coffee floral origins. The sum of fructose and glucose contents of Geteme, Bisana and Coffee floral origin honey samples were $75.62,61.62$ and 61.12, respectively and there were significant difference $(\mathrm{p}<0.05)$ between those three botanical origins although no significant difference $(p>0.05)$ between Bisana and Coffee botanical origins since Geteme floral origin samples of fructose + glucose higher than that of Bisana and Coffee floral origins. Those values shows that, although the values are in agreement with the limit required by the international norms; i.e, $\geq 60 \mathrm{~g} / 100 \mathrm{~g}$. Geteme honey samples are more authentic than Bisana and Coffee since the value (fructose + glucose) high; the quality of honey becomes high.

Table 3.5: Comparison of sugar content of honey samples from different botanical origins

\begin{tabular}{|l|l|l|l|}
\hline Parameter & Geteme & Bisana & Coffee \\
\hline Fructose $(\mathrm{g} / 100 \mathrm{~g})$ & $42.48 \pm 1.14$ & $33.57 \pm 1.49926$ & $35.92 \pm 10.13$ \\
\hline Glucose $(\mathrm{g} / 100 \mathrm{~g})$ & $33.14 \pm 2.87$ & $28.06 \pm 3.18143$ & $25.20 \pm 3.81$ \\
\hline Sucrose $(\mathrm{g} / 100 \mathrm{~g})$ & $0.46 \pm 0.34$ & $0.24 \pm 0.21$ & $0.85 \pm 0.17$ \\
\hline Fructose+ Glucose & 75.62 & 61.62 & 61.12 \\
\hline Fructose/ Glucose & 1.28 & 1.20 & 1.42 \\
\hline
\end{tabular}

Source: Collected honey samples (laboratory analysis result) Values are presented as mean $\pm \mathrm{SD}$

The other important parameter that relates to honey quality includes the fructose/glucose ratio and sucrose content of a sample. In these three studied floral origins, the average fructose/glucose ratios of Geteme, Bisana and Coffee are 1.28, 1.20 and 1.42 respectively. No significant difference $(\mathrm{P}>0.05)$ were observed between Geteme, Bisana and Yirgachefe in their fructose/glucose ratio. So all the values obtained from these floral origins are approximate to the international standard limits; i.e., in the range of 1.22 to 1.30 . This indicates that the studied floral origin honey samples are almost liquid (not granulated).

The apparent sucrose contents of Geteme, Bissana and coffee honey samples studied were an average $0.46 \pm 0.34,0.24 \pm 0.21$, and $0.85 \pm 0.17$ of $\mathrm{g} / 100 \mathrm{~g}$ respectively. No significance difference between those botanical origins and were significantly $(\mathrm{P}<0.05)$ lower than the fructose contents as well as the glucose contents. The international norm established by the Codex Alimentarius Commission requires that a good quality honey should not contain more than $5 \mathrm{~g} / 100 \mathrm{~g}$ sucrose. The values obtained for sucrose contents of the honey samples were all $100 \%$ within the limits of international standards although their contents differs from each other in a few amount. This indicates that, all samples are not adulterated with sugar syrups.

\subsection{Recovery test}

In order to evaluate the accuracy of the method, recovery tests were carried out by recording \% recovery of the spiked amounts of standard sugars. The acceptable recovery value is in the range of $70 \%$ to $120 \%$ as recommended by Codes Alimentarius. The percent recovery was calculated using the equation:

$$
\% \text { Recovery }=\frac{\text { Detected }(=\text { concentration of Spiked sample }- \text { concentration of unspiked sample })}{\text { amount of spike }} \times 100 \%
$$

The calculated recovery values of all trials and averages of the current measurements are summarized in Table 3.6. 
Table 3.6: Average recovery values (\%) of sugar in three selected samples

\begin{tabular}{|c|c|c|c|c|c|c|c|c|c|}
\hline \multirow{2}{*}{$\begin{array}{l}\text { Sample } \\
\text { Codes }\end{array}$} & \multicolumn{3}{|c|}{ Fructose } & \multicolumn{3}{|c|}{ Glucose } & \multicolumn{3}{|c|}{ Sucrose } \\
\hline & spiked & detected & Recovery & spiked & detected & Recovery & spiked & detected & Recovery \\
\hline BGFH & 1.50 & 1.53 & 101.90 & 1.50 & 1.47 & 96.10 & 0.23 & 0.17 & 74.00 \\
\hline KGFH & 1.48 & 1.47 & 99.30 & 1.46 & 1.34 & 91.80 & 0.27 & 0.24 & 90.2 \\
\hline BGMH & 1.51 & 1.53 & 101.50 & 1.49 & 1.40 & 94.00 & 0.26 & 0.22 & 82.9 \\
\hline
\end{tabular}

Table 3.6 shows that the recovery values of fructose and glucose were ranged from 99.30 to $101.90 \%$ with an average of $100.90 \%$ and 91.80 to $96.10 \%$ with an average of $93.97 \%$, respectively. In a similar manner, the recovery value of sucrose ranged from $74.00 \%$ to $90.2 \%$ with an average of $82.37 \%$. This indicates a very good accuracy of the determinations as the values are within the acceptable range ( $70 \%$ to $120 \%$ ).

\subsection{Intermediate Precision}

In order to evaluate the repeatability of the measurement, the relative standard deviation (RSD \%) was calculated and the result is indicated in Table 3.7 below. The low values of the relative standard deviation (RSD \%) and standard deviation (SD) indicate the high precision and the good accuracy of the proposed method. The RSD \% can be calculated as shown below equation.

$$
\text { Relative standard deviation }=\frac{\text { Standard deviation }}{\text { Mean }} \times 100 \%
$$

Table 3.7: RSD of fructose and glucose in different honey samples by percent

\begin{tabular}{|l|l|l|}
\hline Sample & Fructose & Glucose \\
\hline BGFH & 0.366014 & 1.443556 \\
\hline BGCH & 1.297942 & 2.798813 \\
\hline BBFH & 1.457081 & 2.272571 \\
\hline KGFH & 0.433129 & 3.380597 \\
\hline KGCH & 1.525436 & 1.76773 \\
\hline KCCH & 1.486939 & 1.525096 \\
\hline KCFH & 0.731594 & 3.692432 \\
\hline Y/CCFH & 1.314737 & 2.011088 \\
\hline Y/CBFH & 0.603519 & 5.045 \\
\hline
\end{tabular}

The RSD values of fructose in all collected honey samples ranged from $0.366014 \%$ to $1.525436 \%$ with an average of $1.0266 \%$ as shown in Table 3.7. This indicates that the precision of the measurement is high since RSD values are very small. In a similar way the RSD values of glucose in these samples ranges from $1.443556 \%$ to $5.045 \%$ with an average of $2.655 \%$. This observation also shows that the repeatability of measurement is high since the average RSD values are small even though Y/CCFH honey samples have high RSD values than other remaining samples.

\section{CONCLUSIONS}

In this study a comparative evaluation of the quality of locally branded honey samples from respective botanical sites (Bore, Keffa and Yirgachefe for Geteme, Bisana and Coffee botanical origins) have been carried out using high performance liquid chromatography (HPLC) for quantification of sugars . Analysis of variance showed significant variations among the level of sugars as well as other quality parameters of hone samples of different floral origins and geographical sites. Both qualitative and quantitative studies indicated fructose and glucose being dominant in all of the analyzed samples with sucrose being detected in a vanishingly small amount. In conclusion, no indication of adulteration by sugar syrups was detected in the studied samples. Their qualities compare favorably well with samples in many parts of the world and meet most of the international standards. However, the level of the quality parameters may change depending on the nature and time of sampling. Therefore, continuous monitoring is recommended.

\section{Acknowledgment}

The authors acknowledge Ethiopian food, medicine, and health care administration and control authority (EFMHACA) and Ethiopian Conformity Assessment Enterprise (ECAE) for giving permission of their laboratories for sample analysis and Ministry of Education for providing the financial support through Hawassa University (HU).

\section{REFERANCES}

1. Amna, J.; Syed, G.; Iqbal, C.; Atta, U. Application of analytical methods in authentication and adulteration of honey. Food Chemistry.2017, 217, 687-698. 
2. José, M.; Alvarez, S.; Massimiliano, G.; Tamara, Y.; Forbes, H.; Luca, M.; Francesca G. The composition and biological activity of honey. A Focus on Manuka Honey Foods. 2014, 3, 420-432.

3. Asrat, A.; Ermias, B. Food adulteration, its challenges and impacts. Food Science and Quality Management. 2015, 41, 2224- 6088.

4. Kaskoniene, V.; Venskutonis, P.; Ceksteryte, V. Carbohydrate composition and electrical conductivity of different origin honeys from Lithuania. Food Science and Technology.2010, 43, 801-807.

5. Escuredo, O.; Dobre, I.; Fernández, G.; Seijo, C. Contribution of botanical origin and sugar composition of honeys on the crystallization phenomenon. Food Chemistry.2014, 149, 84-90.

6. Balasubramanyam, V. Chemical characteristics of multifloral wild and apiry honey from Western Ghats of Karnataka. The Bioscan.2011, 6, 467-469.

7. Madejczyk, M.; Baralkiewicz, D. Characterization of Polish rape and honeydew honey according to their mineral contents using ICP-MS and F-AAS/AES. AnalyticaChimica Acta.2008, 617, 11- 17.

8. Codex Alimentarius Committee on Sugars. Codex standard 12, revised codex standard for honey. Standards and standard methods.2001, 11, 1-7.

9. Spiteri, M.; Dubin, E.; Cotton, J.; Poirel, M.; Corman, B.; Jamin, E. Data fusion between high resolution 1HNMR and mass spectrometry; Asynergetic approach to honey botanical origin characterization. Analytical and Bioanalytical Chemistry.2016, 408, 4389-4401.

10. Spiteri, M.; Jamin, E.; Thomas, F.; Rebours, A.; Lees, M.; Rogers, K.; Rutledge, N. Fast and global authenticity screening of honey using 1H-NMR profiling. Food Chemistry.2015, 189, 60-66.

11. Horwitz, W.; AOAC, Sugars and sugar products. In Official Methods of Analysis.Association of Official Analytical Chemists International, 16th Edition. Washington, DC. 2000, 2, 44- 68.

12. Muhammad, S.; Saghir, A.; Mirza, H.; Abdul, R.; Sadat, S. A study on the determination of physicochemical properties of honey from different valleys of Gilgit-Baltistan. International Journal of Agricultural Science Research. 2013, 2, 049-053.

13. Fuente, E.; Ruiz-Matute, A.; Valencia-Barrera, R.; Sanz, J.; Castro, I. Carbohydrate composition of Spanish unifloral honeys. Food Chemistry.2011, 129, 1483-1489.

14. Buba, F.; Gidado, A.; Shugaba, A. Analysis of Biochemical Composition of Honey Samples from North-East Nigeria. Biochemistry and Analytical biochemistry.2013, 2,139-152

15. European Economic Community. European economic council directive of 20 December 2002 relating to honey. Journal of Europian Community.2002, 110, 47-50.

16. Wang, J. Chemical composition, characterization, and differentiation of honey botanical and geographical origins. Advances in Food and Nutrition Research.2011, 62, 89-137.

17. Chakir, A.; Romane, A.; Barbagianni, N.; Bartoli, D.; Ferrazzi, P.; Major and trace elements in different types of Moroccan honeys. Australian Journal of Basic and Applied Sciences.2011, 5, 223-231.

18. Karabagias, I.; Badeka, A.; Kontakos, S.; Karabournioti, S.; Kontominas, M. Characterisation and classification of Greek pine honeys according to their geographical origin based on volatiles, physicochemical parameters and chemometrics. Food Chemistry.2014, 146, 548-557.

19. Escuredo, O.; Míguez, M.; Fernández-González, M.; Seijo, M. Nutritional value and antioxidant activity of honeys produced in a European Atlantic area. Food Chemistry.2013, 138, 851-856.

20. Bonté, F.; Desmoulière, A. Composition of different honey origins. Actualites Pharmaceutiques.2013, 531, $18-21$.

21. Suárez-Luque, S.; Mato, I.; Huidobro, J.; Simal-Lozano, J.; Sancho, M.; Rapid determination of minority organic acids in honey by high-performance liquid chromatography. Journal of Chromatography A. 2002, 955, 207-214.

22. Moreira, R.; Maria, C.; Pietroluongo, M.; Trugo, L. Chemical changes in the non-volatile fraction of Brazilian honeys during storage under tropical conditions. Food Chemistry.2007, 104, 1236-1241.

23. Ribeiro, R.; Mársico, E.; Carneiro, C.; Monteiro, M.; Conte -Júnior, C. Detection of honey adulteration of high fructose corn syrup by Low Field Nuclear Magnetic Resonance. Journal of Food Engineering.2014, 135, 3943.

24. Tornuk, F.; Karaman, S.; Ozturk, I.; Toker, O.; Tastemur, B.; Sagdic, O. Quality characterization of artisanal and retail Turkish blossom honeys; Determination of physicochemical, microbiological, bioactive properties and aroma profile. Industrial Crops and Products. 2013. 46, 124-131.

25. Puscas, A.; Hosu, A.; Cimpoiu, C. Application of a newly developed and validated high-performance thinlayer chromatographic method to control honey adulteration. Journal of Chromatography A. 2013, 1272, 132-135.

26. Anklam, E. A review of the analytical methods to determine the geographical and botanical origin of honey. Food Chemistry. 1998, 63, 549-562.

27. Azeredo, L.; Azeredo, M.; Souza, S.; Dutra, V. Protein contents and physicochemical properties in honey samples of Apismellifera of different floral origins. Food Chemistry. 2003, 80, 249 -254. 
28. Mateo, R.; Bosch-Reig, F. Classification of Spanish unifloral honeys by discriminant analysis of electrical conductivity, color, water content, sugars, and pH. Journal of Agricultural and Food Chemistry.1998, 46, 393-400.

29. Terrab, A.; Heredia, F. Characterisation of avocado (Persea Americana Mill) honeys by their physicochemical characteristics. Journal of the Science of Food and Agriculture.2004, 84, 1801-1805.

30. Kukurova, K.; Karovicova, J.; Kohajdova, Z.; Bilikova, K. Authentication of honey by multivariate analysis of its physicochemical parameters. Journal of Food and Nutrition Research.2008, 47, 170-180. 